\title{
Demand for healthcare by the elderly in developing countries
}

\author{
Yinka Kehinde Binuomoyo ${ }^{1}$, Abimbola Oluseyi Ogunsola ${ }^{2}$ \\ Stanbic IBTC \& Department of Economics, Lagos State University, Ojo, Nigeria \\ Department of Physiology, Ben Carson Snr. School of Medicine, Babcock University, llisan-Remo, Nigeria
}

\section{INTRODUCTION}

Throughout history, humanity has been at crossroads on the issue of healthcare delivery. This applies to both developed and developing nations, faced with challenges in their citizens' access to healthcare services. Recent discussions have focused on public health and ownership of the healthcare system. However this does not take into cognizance the economics of healthcare services particularly the demand-side challenges faced by the elderly people in developing countries like $\mathrm{Ni}$ geria.

A number of development policies have been conceived in Nigeria over the years particularly following the conception and implementation of the National Economic and Empowerment Development Strategy (NEEDS) policy in 2004 [1] that has continued to attract further research and elicit responses and analyses from various stakeholders. Social programmes constitute the major part of these public policies engineered around development of which health is a major focus. The need to address healthcare challenges is justified by the saying that 'health is wealth', and because it assures life. Yet, healthcare programmes like other tokens of governance are often negotiated within closed circles of policy elites with little or no reference made to the preferences of the less-privileged citizens [2].

Ruff et al. [3] emphasized the necessity of considering both the demand-side and supply-side factors in healthcare policymaking and planning. The analysis of Sunkanmi Odubunmi [4] upon which this editorial is based, though much more applies to policymakers in the effective management of the health system, it nevertheless addresses the demand-side constraints erected by the supply-side factors. The supply-side system is thus important in analysing the demandside factors for effective healthcare delivery.

\section{A SUMMARY AND CRITIQUE OF SUNKANMI ODUBUNMI'S POINT OF VIEW}

Based on Farrell et al. [5], the demand-side factors of healthcare services refer to those factors that affect the pattern of usage and the actual demand for the services, which could be influenced by multiple factors like burden of illness, population preferences and related healthcare consumption patterns. On the other hand the supply-side factors refer to those factors related to the supply of human, physical and other resources required to deliver effective healthcare services.

One of the main themes in Odubunmi's article [4] is the consideration of the factors that influence health-seeking behaviour and access to health services (both simply referred to as demand for healthcare services). Odubunmi observed that the focus of health policy interventions has mostly been on reducing the supply barriers, such as improving personnel quality, protocols of treatment, enhancing availability of supplies and improving the ambience of health facilities [6], and noted that the supply-side is not sufficient to solve the country's health problems, but that the demand-side is equally important $[7,8]$. Even with these interventions, they do not holistically address the barriers to accessing health services by the elderly in low-income countries like Nigeria.

Odubunmi noted that employing psycho-social analysis on the elderly during their episodes of illness will help reduce healthcare cost attributable to the specific case. Factors like income, cost of care, education, social norms and traditions, and the quality and appropriateness of the services provided are seen as key factors determining access to appropriate healthcare services. Individuals make decisions from a number of accumulated advices, and within risks and benefits, as well as available resources [9]. These decisions are
Corresponding author Yinka Kehinde Binuomoyo ykbinuomoyo@gmail.com

\section{Disclosure}

The authors have no conflicts of interest to declare. 
reflected in the choices they make, governed by the demand factors.

Because policymakers own the perception that influence public policies and decisions on the system, it is important for them to understand the country's healthcare system very well. And of course, Odubunmi agrees with this position, that "a good understanding of the Nigerian healthcare system will help in redefining the objectives of national healthcare policy as it affects the elderly" [4]. Notwithstanding, the dynamics of healthcare decision processes of households still fall under the health-seeking behaviour earlier noted.

Odubunmi's article appears to be centred more on the consumption aspect of healthcare over demand for the services. This is evident in the theoretical underpinning of the system where he advances the life-cycle theory (LCT) in explaining the consumers' demand (or rather, consumption) of healthcare services. While LCT analyses an individual's post-retirement income or benefits and is in fact applicable to the elderly (Odubunmi may indeed be right on here considering the fact that income is an important factor that determines demand), post-retirement income in developing countries applies more to employed workers of formal business set-up which is small in the case study country's equation, while the informal sector is large, mostly poor and rural, producing as subsistent setup, without savings or any post-retirement plan. Neither does the government have social security programmes to cater for the vulnerable elderly people in this setting thereby, deepening the scourge of poverty.
It is important to note that the insufficient income of the household (or family) is what essentially goes into paying for the healthcare services enjoyed by the elderly. Odubunmi noted that healthcare demand among the elderly is higher than among the young ones and within the constraint of poverty, it is only the government than can help them bear the burden of healthcare expenditure.

\section{CONCLUSIONS}

While though choices of healthcare services differ across the different six geo-political regions of Nigeria (significantly influenced by different demographic factors like age, education, sex, income and household expenditure, household size, family structure, as well as severity of illness), the situation around the healthcare system is the same. In a way, the supply-side factors, just as the demand variables, play their own critical roles. The supply-side factors which could be addressed here include the ease or structure of access to healthcare somewhat the responsibilities of government, consultation or ancillary fees and transport costs. Our aim was to lend credence to the critical role of government in elderly care at least for a poor country like Nigeria through making available social security programmes in form of cash, drugs, food items and other goods. Furthermore we will like to encourage the interaction between policymakers and other stakeholders in order to stimulate answers to the Nigeria's healthcare problems. By these, the moral obligation of good governance as reflected in the provision of a good healthcare system will be profound.

\section{REFERENCES}

1. Nigerian National Planning Commission (NNPC). Meeting everyone's needs: National Economic Empowerment and Development Strategy. Abuja: NNPC, 2004

2. Bratton M, Coulibaly M, Machado F. Popular views of the legitimacy of the state in Mali. Can J Afr Stud 2002; 36: $197-238$

3. Ruff B, Mzimba M, Hendrie S, et al. Reflections on health-care reforms in South Africa. J Public Health Policy 2011; 32: S184-92

4. Odubunmi S. Demand for healthcare by the elderly in Nigeria. In: Olaniyan O, Lawanson AO, Olubajo O (Eds). Economics of Health System Governance and Financing in Nigeria. Ibadan: Ibadan University Press, 2012; pp. 255-76

5. Farrell D, Henke NP, Mango PD. Universal principles for health care reform. The McKinsey Quarterly 2007; 1: 87-97

6. Ensor, T Cooper S. Overcoming barriers to health service access: influencing: the demand side. Health Policy Plan 2004; 19: 69-79

7. Ringel SJ, Hosek SD, Vollaard BA, et al. The elasticity of demand for health care: a review of the literature and its application to the military system. RAND Health, 2002. Available at: http://www.rand.org/pubs/monograph_reports/2005/MR1355.pdf (last accessed December 2015) 
8. Akin JS, Guilkey DK, Denton EH. Quality of services and demand for healthcare in Nigeria: a multinomial probit estimation. Soc Sci Med 1995; 40: 1527-37

9. World Bank Publications. The demand for health care services In: Principles of Health Economics for Developing Countries. World Bank, 2015. Available at: http://siteresources.worldbank.org/INTHSD/Resources/topics/HealthEconomics/PHE_Ch4.pdf (last accessed December 2015) 